\title{
EFFECTS OF THE HEAT TREATMENT TEMPERATURE ON COMPOSITION, MICROSTRUCTURE AND IN VITRO MINERALIZATION OF ALKALI TREATED TITANIUM
}

\author{
Serhii TKACHENKO, Adelia KASHIMBETOVA, Pavel GEJDOŠ, Carolina OLIVER-URRUTIA, \\ Mariano CASAS-LUNA, Martin JULIŠ, Edgar B. MONTUFAR, Ladislav ČELKO \\ CEITEC - Brno University of Technology, Brno, Czech Republic, EU, \\ serhii.tkachenko@ceitec.vutbr.cz,ladislav.celko@ceitec.vutbr.cz
}

https://doi.org/10.37904/metal.2021.4260

\begin{abstract}
Titanium shows minimal encapsulation when implanted in bone tissue and develops a direct interfacial contact with bone. The higher surface roughness of titanium leads to a stronger anchorage in comparison with polished smooth surfaces, but the fixation is due to mechanical interlocking rather than chemical bonding. Treatment of titanium with sodium hydroxide solution promotes a surface modification that induces the formation of a carbonated apatite layer, which produces a strong chemical fixation with bone in vivo. The aim of this work was to study the effects of heat treatment temperature on the microstructure and chemical composition of the surface of alkali-treated titanium, and correlate the results with the mineralization capacity in vitro. The results showed that after the alkali treatment the surface of titanium had a complex microstructure with submicron porous features. The crystallinity and microstructure of the titanium surface slightly varied with the heat treatment. The general observation was that the slight increment of the anatase content at surface level together with smaller pore size promoted the formation of apatite.
\end{abstract}

Keywords: Titanium, surface modification, alkali treatment, mineralization, bioactivity

\section{INTRODUCTION}

Biomaterials are implanted in the tissues of the human body for the treatment, augmentation or replacement of biological functions as a part of a medical device. Biomaterials interact with biological systems and they should not trigger any adverse local or systemic effect but rather generate the most appropriate beneficial response that optimizes the performance of the medical therapy [1]. Due to unique combination of properties, such as low Young's modulus, high specific mechanical strength, corrosion resistance and biocompatibility, titanium and its alloys have become the most widely used metallic materials for the fabrication of orthopaedic and dental implants. Titanium produces minimal side effects in the human body. Furthermore, having a Young's modulus similar to that of human bone titanium demonstrates better biomechanical compatibility in comparison with other implantable metals. Unlike other non-resorbable biocompatible materials, titanium shows minimal encapsulation when implanted in vivo and develops a direct interfacial contact with bone. The capability to form the direct contact with bone without the formation of fibrous layer is known as bioactive osseointegration [2]. However, the bioactivity of titanium requires to be further improved in order to extend the service life of orthopaedic implants. Current research efforts are focused on control of the micro- and nanoporosity of titanium surface to direct cell orientation, cell morphology, and cytoskeleton arrangement [3], and thereby, to improve the anchorage of the implant with bone. Developing surface roughness by sandblasting, acid etching or anodic oxidation produces stronger osseointegration in comparison with polished smooth surfaces $[4,5]$, but the fixation is due to mechanical interlocking rather than to chemical bonding [6]. The production of hydroxyapatite or bioactive glass coatings on titanium is another approach to increase the bioactivity of the implant [7] as these coatings develop a tight chemical bond with living bone. The mechanisms that result in the chemical union with bone are complex and vary between hydroxyapatite and bioactive 
glasses. In general, the union requires ionic interaction at surface level with the physiological microenvironment that induce the precipitation of a carbonated apatite layer $[2,8]$. The growth of the apatite layer and its transformation from amorphous to crystalline generate a chemical and mechanical stable linkage with bone $[2,8,9]$. Currently, it is accepted that the formation of the carbonated apatite layer can be replicated in vitro by the immersion of the bioactive material in simulated body fluids (SBF) that mimic the ionic composition of the human blood plasma [9]. Furthermore, the formation of the apatite layer in vitro is indicative of the potential chemical fixation of the implant with bone in vivo [9]. In vitro studies on SBF allowed to discover that titanium surfaces treated with sodium hydroxide solutions induce the formation of a carbonated apatite layer on their surface [10], later confirming that a strong fixation with bone can be formed in vivo [6]. The superior bioactivity of titanium after alkali and heat treatments was attributed to the presence of a titania hydrogel at the surface that allowed apatite nucleation [11]. The aim of this work was to study the microstructure and chemical composition of the surface of alkali treated titanium disks after heat treatment at different temperature and correlate the results with the apatite mineralization in vitro.

\section{MATERIALS AND METHODS}

Commercially pure titanium disks (CP-Ti, grade 2; diameter of $12 \mathrm{~mm}$ ) were polished with no. 1200 abrasive sand paper and then washed in an ultrasonic cleaner. A typical surface treatment procedure consists of soaking a titanium disk in $5 \mathrm{M} \mathrm{NaOH}$ solution $(5 \mathrm{ml})$ at $60^{\circ} \mathrm{C}$ for $24 \mathrm{~h}$ and subsequent heat treatment in the temperature range of 300 to $600{ }^{\circ} \mathrm{C}$ for $1 \mathrm{~h}$. The surface morphology of the disks after each step of the treatment was examined using a scanning electron microscope (SEM) equipped with electron dispersive $X$ Ray (EDX) detector. X-ray diffraction (XRD) and X-ray photoelectron spectroscopy (XPS) were used to determine the phase and elemental composition of the samples treated under different conditions. In vitro mineralization test was performed on treated samples in accordance with Kokubo's methodology at $37^{\circ} \mathrm{C}$ for 7 days (30 ml/disk) [9]. Sample codes are in accordance with performed treatment: AT - alkali treatment; $\mathrm{AT}+\mathrm{HT} 300 / 500 / 600$ - alkali and subsequent heat treatment at 300,500 , or $600{ }^{\circ} \mathrm{C}$; SBF300/500/600 - alkali + heat treatment + soaking in simulated body fluid.

\section{RESULTS AND DISCUSION}

Figure 1 shows that unlike polished samples the treated samples had a complex surface microstructure with submicron porous features resulting from the alkali treatment. The size of the pores was refined with the increment of the heat treatment temperature.
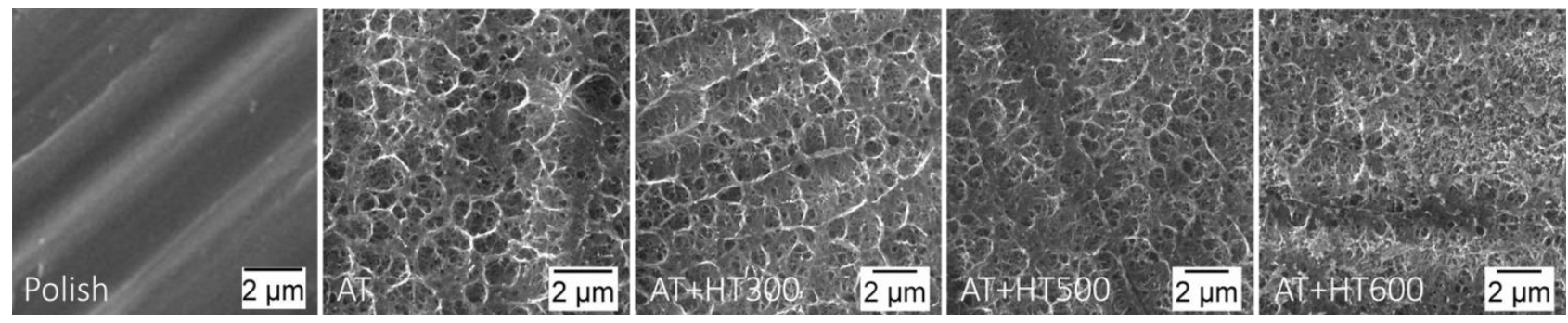

Figure 1 Microstructure of the sample surfaces before and after alkali treatment and heat treatment at different temperature

XRD data showed that for all the studied conditions the most intense peaks belonged to titanium (Figure 2). Subsequent heat treatmentled to the formation of crystalline titanium dioxides, identified as rutile and anatase. Moreover, with increasing temperature of heat treatment, the intensity of the oxide peaks also raised, which indicates an increase in the volume fraction of oxides. In particular, the formation of anatase is relevant 
because induces the in vitro apatite nucleation [12]. Presence of sodium titanate was not observed by XRD, likely, due to a very low content of the phase or its amorphous nature.

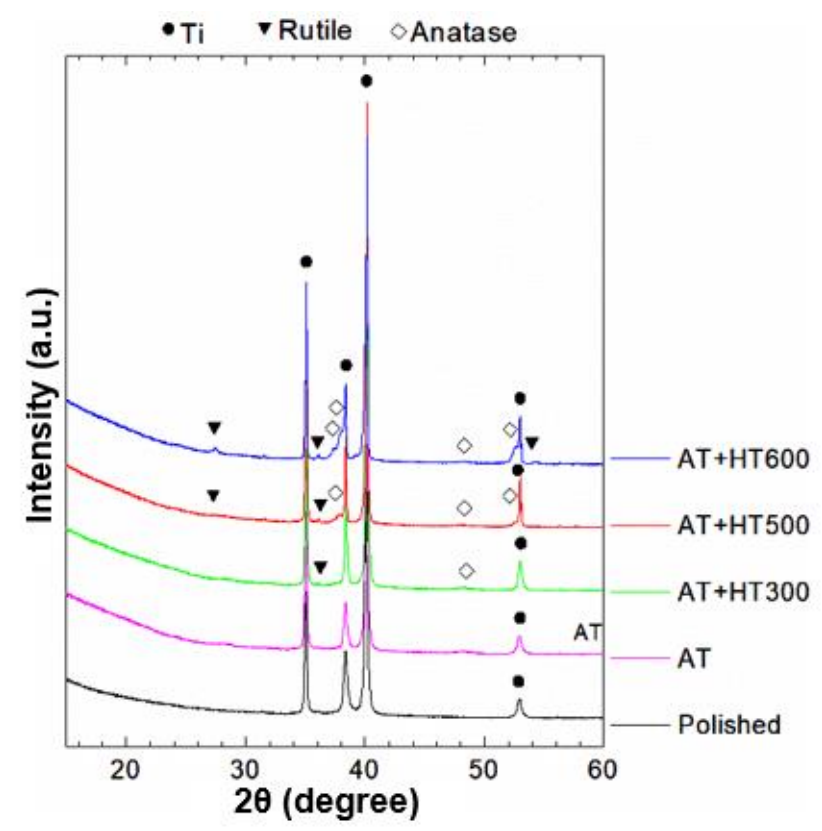

Figure 2 XRD patterns of the sample surfaces after alkali treatment and heat treatment at different temperature

Elemental analysis via EDX demonstrated similar results to those obtained by XRD, with increased mass fraction of oxygen when the temperature of heat treatment increased (Figure 3). The presence of sodium was also evident, which may confirm the coexistence of titanium dioxide and sodium titanate phases.

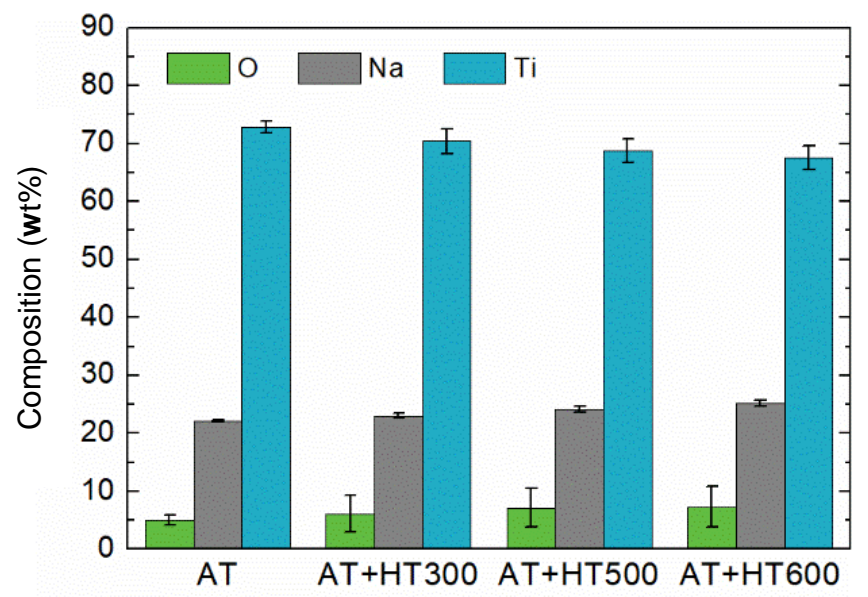

Figure 3 EDX elemental analysis of the sample surfaces after alkali treatment and heat treatment at different temperature

The surface composition of Ti samples analyzed by XPS allowed establishing that the major elements on all the surfaces were $\mathrm{O}, \mathrm{Ti}, \mathrm{Na}$, and $\mathrm{C}$ (Figure 4). This elemental composition agrees with the data obtained by XRD and EDX analyses and with the expected composition of the surface. Considering the high-resolution XPS spectra, noticeable differences in the $O 1$ s peak deconvolutions and subsequent positions were identified. $\mathrm{O} 1 \mathrm{~s}$ peak contained two peaks corresponding to $\mathrm{O}^{2-}$ at $\sim 529.7 \mathrm{eV}$ and $\mathrm{OH}^{-}$at $531.5 \mathrm{eV}$, intensities that slightly increased after exposure to the heat treatment as it was expected due to the formation of titanium dioxides. 
Moreover, the presence of $\mathrm{OH}^{-}$supports the presence of an amorphous hydrogel, most probable sodium titanate hydrogel [11]. In agreement, the position of Ti $2 p$ peaks confirmed the presence of titanium dioxide, fraction of which slightly increased after the heat treatment. The intensity of $\mathrm{Na}$ 1s peak decreased with heat treatment presumable due to thermal oxidation. The presence of $C$ is explained by adventitious contamination typical for samples that have been exposed to the atmosphere.
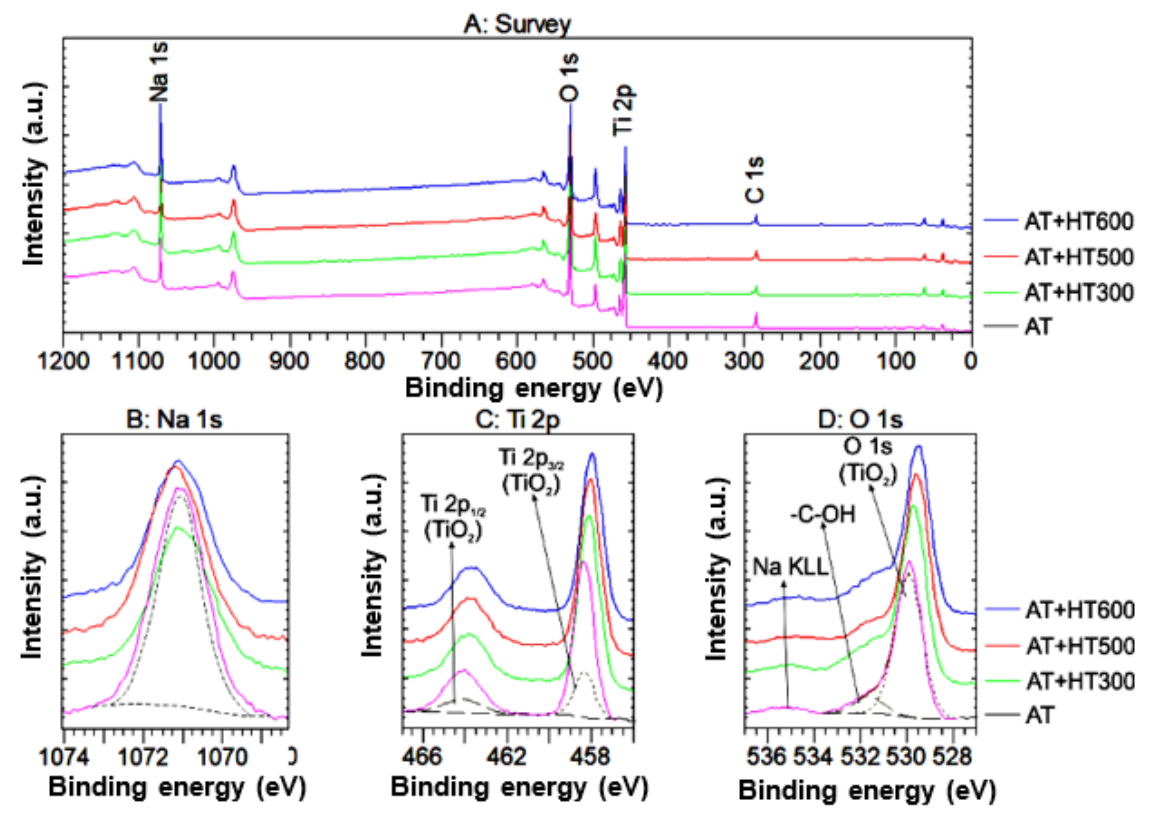

Figure 4 XPS elemental analysis of the sample surfaces after alkali treatment and heat treatment at different temperature

In vitro mineralization test showed the presence of calcium and phosphorous rich precipitates in the alkali treatedsamples (Figure 5), the composition corroborated by the elemental analysis by XPS (Figure 6). The amount of calcium phosphate precipitates was relatively inferior with respect to the amount observed in previous studies [10], so the difference was attributed to the shorter experimental time ( 7 days against 4 weeks) and not having the SBF renewed regularly. The precipitates were located in the pores formed after alkali treatment. Moreover, heat treatment at 300 or $500{ }^{\circ} \mathrm{C}$ did not cause any noticeable difference in the amount, morphology and chemical composition of the precipitates with respect to the solely alkali treated sample. In contrast, the quantity and size of calcium phosphate precipitates was increased in the sample heat treated at $600{ }^{\circ} \mathrm{C}$. However, it is not easy to elucidate a single reason for the improvement, since the crystalline composition, crystallinity and morphology of the microstructure varied simultaneously. The general observation is that higher crystallinity and major content of anatase at surface level, together with smaller pore size of the surface features, promote the formation of the apatite layer. Some calcium phosphate precipitates were observed sporadically on the surface of the as-polished samples.
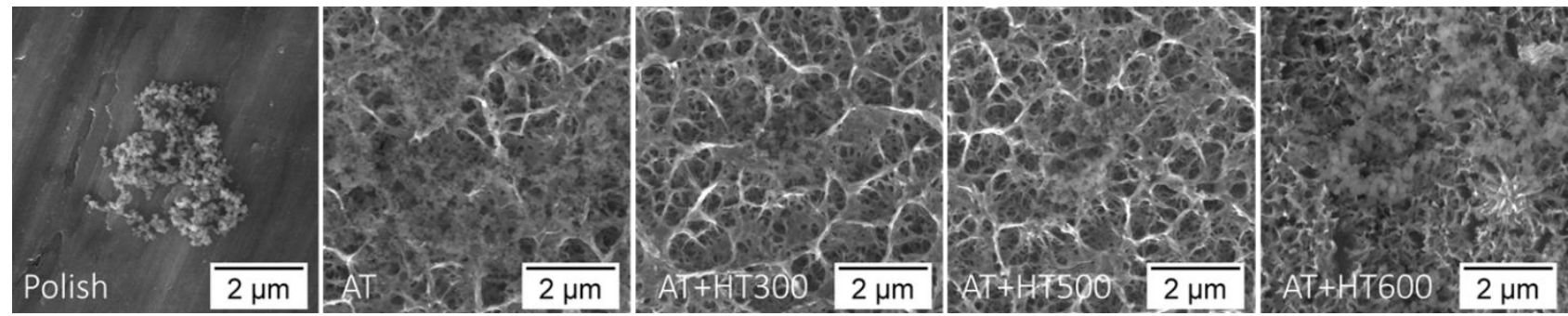

Figure 5 Formation of calcium and phosphorous rich precipitates after 7 days of immersion in SBF 


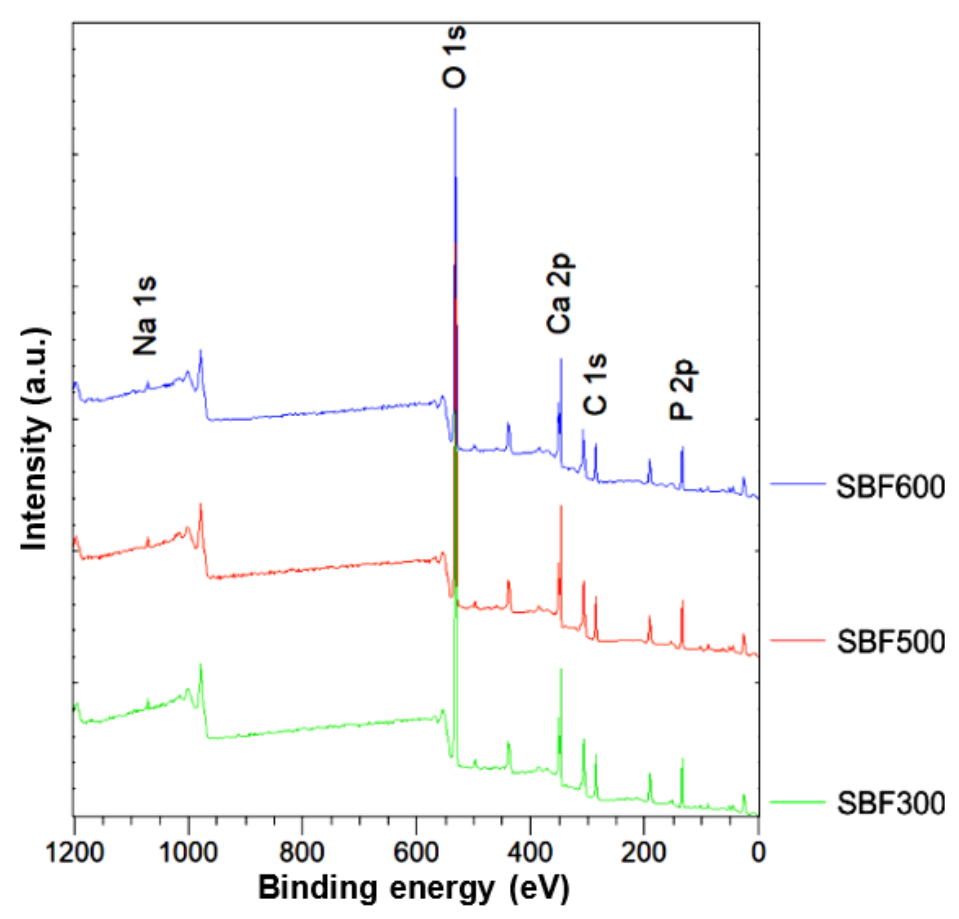

Figure 6 XPS elemental analysis of the sample surfaces after 7 days of immersion in SBF. The presence of calcium and phosphorous confirms the formation of an apatite layer

\section{CONCLUSION}

Alkali surface treatment by immersion in $\mathrm{NaOH}$ has demonstrated simple ability for the activation of the titanium surface, which allowed the in vitro mineralization of titanium. The method is low cost and feasible for the surface treatment of complex titanium implants, such bone tissue engineering scaffolds, in large scale. It was observed thathigher crystallinity and formation of anatase at surface level, together with refined microstructural features promote the precipitation of the apatite layer in vitro.

\section{ACKNOWLEDGEMENTS}

This work was supported by the Czech Science Foundation (grant 19-22662S). A.K. acknowledges the Brno Ph.D. Talent scholarship founded by the Brno City Municipality and the project CEITEC VUT/FAST-J-21-7305. C.O.U. acknowledges the CONACYT grant 2020-000021-01EXTV-00235. Part of the work was carried out on the devices purchased by CEITEC Nano Research Infrastructure supported by MEYS-CR (LM2018110).

\section{REFERENCES}

[1] WILLIAMS, D.F. On the mechanisms of biocompatibility. Biomaterials. 2008, vol. 29, no. 20, pp. $2941-2953$.

[2] LEGEROS, R.Z. Calcium phosphate-based osteoinductive materials. Chemical reviews. 2008, vol. 108, no. 11, pp. $4742-4753$.

[3] KHANG, D., LU, J., YAO, C., HABERSTROH, K.M., WEBSTER, T.J. The role of nanometer and sub-micron surface features on vascular and bone cell adhesion on titanium. Biomaterials. 2008, vol. 29, no. 8, pp. 970-983.

[4] HE, F.M., YANG, G.L., LI, Y.N., WANG, X.X., \& ZHAO, S.F. (2009). Early bone response to sandblasted, dual acid-etched and $\mathrm{H}_{2} \mathrm{O}_{2} / \mathrm{HCl}$ treated titanium implants: an experimental study in the rabbit. International journal of oral and maxillofacial surgery. 2009, vol. 38, no. 6, pp. 677-681. 
[5] REN, B., WAN, Y., WANG, G., LIU, Z., HUANG, Y., WANG, H. Morphologically modified surface with hierarchical micro-/nano-structures for enhanced bioactivity of titanium implants. Journal of Materials Science. 2018, vol. 53, no. 18, pp. 12679-12691.

[6] YAN, W.Q., NAKAMURA, T., KOBAYASHI, M., KIM, H.M., MIYAJI, F., KOKUBO, T. Bonding of chemically treated titanium implants to bone. Journal of Biomedical Materials Research. 1997, vol. 37, no. 2, pp. $267-275$.

[7] KOKUBO, T., YAMAGUCHI, S. Biomimetic surface modification of metallic biomaterials. Woodhead Publishing. 2015, pp. 219-246.

[8] HENCH, L.L. Bioceramics. Journal ofthe American Ceramic Society. 1998, vol. 81, no. 7, pp. 1705-1728.

[9] KOKUBO, T., TAKADAMA, H. How useful is SBF in predicting in vivo bone bioactivity? Biomaterials. 2006, vol. 27, no. 15, pp. 2907-2915.

[10] KOKUBO, T., MIYAJI, F., KIM, H.M., \& NAKAMURA, T. Spontaneous formation of bonelike apatite layer on chemically treated titanium metals. Journal of the American Ceramic Society. 1996, vol. 79, no. 4, pp. 1127-1129.

[11] LI, P., KANGASNIEMI, I., DE GROOT, K., KOKUBO, T. (1994). Bonelike hydroxyapatite induction by a gelderived titania on a titanium substrate. Journal of the American Ceramic Society. 1994, vol. 77, no. 5, pp. 13071312.

[12] UCHIDA, M., KIM, H.M., KOKUBO, T., NAKAMURA, T. Compositional and structural dependence of apatite formation on titania gel in simulated body fluid. In: Sixth World Biomaterials Congress. Kamuela (Big Island), 2000, p.1308. 